\title{
Defining Issues Test-2: Fidedignidade da Versão Brasileira e Ponderações acerca de seu Uso em Pesquisas sobre Moralidade
}

\author{
Alessandra de Morais Shimizu ${ }^{1}$ \\ Universidade Estadual Paulista, Presidente Prudente
}

\begin{abstract}
Resumo
Este estudo teve como objetivo avaliar a fidedignidade da tradução e adaptação brasileira do Definig Issues Test (DIT) -2, assim como realizar algumas ponderações sobre a utilização desse instrumento e do DIT -1 em pesquisas sobre moralidade. Os testes DIT-1 e DIT-2 foram aplicados em 621 jovens brasileiros, proporcionalmente distribuídos conforme a cidade de procedência (Floriano/PI, Erechim/RS e Marília/SP), o tipo de escola (pública e particular) e o ano escolar freqüentado ( $8^{\circ}$ ano do ensino fundamental e $3^{\circ}$ ano do ensino médio). Em relação à fidedignidade, notou-se que, apesar de os valores alcançados serem próximos àquele obtido na tradução e adaptação do DIT-1, revelam-se bem menores que os verificados nas versões originais americanas. Na verificação das pontuações alcançadas nos testes, foi observada a existência de tendências distintas no interior da amostra investigada, marcadas pelas variáveis controladas. Foram tecidas considerações sobre a validade e a interpretação desses testes.
\end{abstract}

Palavras-chave: Desenvolvimento moral; instrumentos de medida de julgamento moral; abordagem neo-kohlberguiana baseada no DIT.

Defining Issues Test-2: Reliability of the Brazilian Version and Considerations Concerning its Use in Studies on Morality

\begin{abstract}
This study aims to evaluate the reliability of a Brazilian translation and adaptation of the Defining Issues Test (DIT) -2 , as well as to make considerations concerning the use of this tool and of DIT -1 in studies on morality. The DIT -1 and DIT -2 were administred to 621 Brazilian youngsters, equally distributed according to the city of origin (Floriano/PI, Erechim/RS and Marilia/SP), the kind of school (public or private) and the school year attended ( $8^{\text {th }}$ grade and $11^{\text {th }}$ grade). Regarding the reliability, it was noticed that although the values achieved were close to that one obtained in the translation and adaptation of DIT -1, they revealed themselves much lower than the ones verified in the American original versions. When checking the scores achieved in the tests the existence of some tendencies within the investigated sample was observed. Some considerations regarding the validity and interpretation of these tests are made. Keywords: Moral development; moral judgment weighing tool; neo-kohlberguiana approaching based on DIT.
\end{abstract}

Este estudo teve como objetivo avaliar a fidedignidade da tradução e adaptação brasileira do Definig Issues Test-2 e realizar algumas ponderações sobre a utilização desse instrumento e do Definig Issues Test -1 em pesquisas sobre moralidade.

Como os Definig Issues Tests 1 e 2 foram construídos com base na abordagem kohklberguiana, introduziremos o leitor aos principais aspectos dessa linha teórica.

Para Kohlberg (1992), o desenvolvimento moral apresenta um componente básico cognitivo estrutural que consiste na capacidade dos indivíduos de fazer juízos e julgamentos morais com base em aspectos argumentativos e justificadores. O desenvolvimento do juízo moral, então, ocorreria através de estágios; esses sistemas organizados de pensamento formam uma seqüência invariável e progressiva, sem retrocesso, de modo que o tipo de raciocínio de um estágio superior inclui o do inferior. Dessa forma, o desenvolvimento do raciocínio moral se produz em um movimento ascendente, percorrendo três níveis e seis estágios.

${ }^{1}$ Endereço para correspondência: E-mail: ashimizu@flash.tv.br
No primeiro nível moral - o pré-convencional (Estágios1 e 2), a criança percebe a existência das regras, do bem e do mal; no entanto, não as compreende como formas de manter as normas sociais convencionais. Para ela, o valor moral está ainda localizado em acontecimentos externos e baseado no poder físico de quem estipula a regra moral.

O nível convencional (Estágios 3 e 4) é representado por uma quantidade significativa de adolescentes e adultos da sociedade contemporânea. O termo "convencional" significa conformidade e manutenção das normas mediante a identificação do indivíduo com a ordem social ajustada, a fim de preservar a lealdade para com a família, o grupo ou a nação.

Passível de ser alcançado apenas por uma minoria de adultos, está o nível pós-convencional (Estágios 5 e 6). Nessa fase a lei é legitimada quando cumpre seu papel de garantir a proteção dos direitos de todos; no entanto, sob o ponto de vista do indivíduo que se encontra nesta fase, ela nem sempre o faz, podendo entrar em conflito com algum aspecto moral. Dessa forma, as decisões morais corretas vão além do âmbito sócio-legal, pautando-se na consciência de direitos baseados em princípios éticos universais. 
Apesar da relevância dada pelo meio científico à teoria de Kohlberg e sua metodologia de investigação, muitas críticas lhes têm sido remetidas. Alguns teóricos adeptos à abordagem kohlberguiana- em especial Rest, Narvaez, Bebeau e Thoma (1999), idealizadores dos Defining Issues Tests 1 e 2, cientes dos principais problemas teóricos e metodológicos da teoria, têm se empenhado na reformulação de alguns de seus aspectos.

Rest e colaboradores (1999) descrevem o desenvolvimento moral por meio de "esquemas de desenvolvimento": "esquema de interesse pessoal", que corresponde aos Estágios 1 e 2; "de manutenção das normas", correspondente aos Estágios 3 e 4, e "pós-convencional", relacionado aos Estágios 5A, 5B e 6. Esses autores utilizam o termo esquema para sinalizar que não consideram $\mathrm{o}$ desenvolvimento moral uma mudança abrupta de um degrau para outro, ocasionada pelo tempo - como Kohlberg considerara, utilizando a noção de estágios piagetianos duros. Para os pesquisadores, o desenvolvimento moral é um movimento ascendente, com mudanças graduais em direção à preferência por pensamentos morais mais desenvolvidos e o uso restrito de um estágio em detrimento de outro (estágios mais altos sendo mais utilizados e estágios mais baixos tendo seu uso diminuído, ao longo da evolução do indivíduo). Assim, a avaliação do desenvolvimento não deve consistir no enquadramento do indivíduo em determinados estágios, mas na análise do grau com que o sujeito utiliza vários tipos de pensamentos.

A primeira versão do DIT (Defining Issues Tes‡) - a qual denominamos de DIT-1 - foi elaborada por Rest e colaboradores em 1979 (citado em Rest, 1986). O teste é constituído por seis dilemas morais - versão longa - ou três dilemas (versão curta); para cada um deles o sujeito deve avaliar 12 alternativas de respostas, havendo uma escala de cinco graus de importância para a resolução. $\mathrm{O}$ avaliado deve selecionar hierarquicamente as quatro alternativas que considera mais importantes para a solução do dilema. Dessa forma, é possível obter-se um escore, denominado de índice $\mathrm{P}$, que representa a percentagem de nível pós-convencional (Estágios 5A, 5B, e 6) podendo-se, ainda, visualizar os padrões de respostas que os sujeitos oferecem em cada Estágio (2, 3, 4, 5A, 5B, e 6) assim como as respostas A, antiestablishment, a quais não serão analisadas no presente estudo.

O DIT-1 foi traduzido, inicialmente, por Bzuneck, em 1979 (Koller \& cols., 1994), que o denominou, em língua portuguesa, de "Teste de Julgamento de Situações"; reformulado, de acordo com o contexto brasileiro, por Camino e Luna (1989), passou a ser chamado de "Opiniões sobre Problemas Sociais".
Atualmente existe uma nova versão americana desse tipo de instrumento, elaborada por Rest e Narvaez(1998), denominada de DIT-2. Em estudos feitos até o momento, comparando-se o DIT-1 com o DIT-2, tem-se demonstrado que este é mais moderno, mais curto, possui instruções mais claras e dinâmicas, invalida um número menor de sujeitos pelo teste de não-confiabilidade e parece produzir uma tendência sutilmente mais forte de validade e confiabilidade. Apesar desses aspectos positivos já vislumbrados em alguns estudos com o DIT-2, Rest e Narvaez (1998) advertem, no entanto, sobre a necessidade da realização de mais pesquisas a respeito, uma vez que já existem centenas de estudos com o DIT-1, com dados colhidos em mais de 45000 indivíduos, enquanto que o número de pesquisas com o DIT-2 é muito limitado.

Rest e colaboradores (1999) explicitam também os critérios de validade sobre os quais a pesquisa com o DIT (tratam especialmente do DIT-1, sobre o qual há um número significativamente maior de pesquisas) se sustenta: diferenciação de grupos em relação a medidas mais altas ou mais baixas de julgamento moral, indicando especialmente uma diferenciação mais forte em relação à variável "nível educacional"; demonstração de significante mudança ascendente em estudos longitudinais; sensibilidade a intervenções direcionadas à promoção de raciocínios morais, por meio de sua utilização em pré e pós-teste para se medir a efetividade dos programas de Educação Moral; evidência de desenvolvimento hierárquico, ou seja, de que escores mais altos indicam um desenvolvimento moral mais avançado e melhor do que escores mais baixos (por intermédio de estudos que correlacionam positivamente os escores do DIT com medidas de compreensão moral, desenvolvimento de ego, operações formais, julgamento reflexivo); previsibilidade significativa do comportamento da vida real demonstrada pela correlação do DIT com medidas de comportamento pró-social ou anti-social e com atitudes e escolhas políticas; e adequada confiabilidade comprovada por: consistência interna apropriada; diversas verificações de confiabilidade para a detecção e invalidação do teste e resultados em teste-reteste e no Guttman.

Rest e colaboradores (1999) reconhecem, no entanto, que os testes possuem alguns problemas, em especial: os participantes podem preenchê-los aleatoriamente, fornecendo dados falsos, e respondê-los de forma diferente daquela planejada por seus criadores; seus itens podem parecer ambíguos para alguns participantes ou ocasionar reações peculiares; ao contrário da entrevista, que subestima o desenvolvimento da pessoa (escassez de Estágios 5 e 6), o DIT pode superestimá-lo. 
Lind (2000) aponta uma importante característica do DIT evidenciada por um estudo de Emler, Renwick e Malone (1983, citado em Lind, 2000). Nessa pesquisa, solicitou-se que metade dos sujeitos preenchesse o DIT da forma como eles imaginavam que um estudante liberal o responderia e à outra metade foi pedido que o preenchessem como um estudante conservador o faria. A partir de seus resultados, pôde-se observar que o índice P pode ser facilmente simulado pelos sujeitos, sendo então os escores do DIT passíveis de falsificações para melhor quando existe uma proposta nesse sentido.

\section{Método}

\section{Participantes}

Os participantes de nossa pesquisa foram 621 jovens brasileiros, distribuídos, conforme a região de procedência, o tipo de escola (pública e particular) e o ano escolar freqüentado, da seguinte maneira:

- 241 jovens de Erechim (RS), sendo 58 do $8^{\circ}$ ano do ensino fundamental de escola pública, $63 \mathrm{do} 8^{\circ}$ ano do ensino fundamental de escola privada, $59 \mathrm{do} 3^{\circ}$ ano do ensino médio de escola pública e 61 do $3^{\circ}$ ano do ensino médio de escola privada;

- 209 jovens de Floriano (PI), sendo 54 do $8^{\circ}$ ano do ensino fundamental de escola pública, $54 \mathrm{do} 8^{\circ}$ ano do ensino fundamental de escola privada, $54 \mathrm{do} 3^{\circ}$ ano do ensino médio de escola pública e 47 do $3^{\circ}$ ano do ensino médio de escola privada;

- 171 de Marília (SP), sendo 50 do $8^{\circ}$ ano do ensino fundamental de escola pública, 41 do $8^{\circ}$ ano do ensino fundamental de escola privada, $52 \mathrm{do} 3^{\circ}$ ano do ensino médio de escola pública e 28 do $3^{\circ}$ ano do ensino édio de escola privada.

\section{Materiais e Instrumentos}

$\mathrm{Na}$ pesquisa de campo foram utilizados os seguintes instrumentos de coleta de dados, conforme a ordem de aplicação:

- DIT -1 / versão curta (Defining Issues Test - Short 3 / Story Form, Rest, 1979), traduzido por Bzuneck (1979) e reformulado por Camino e Luna (1989);

- DIT-2 (Defining Issues Test - 2, Rest \& Narvaez, 1998), traduzido e adaptado por Biaggio, Shimizu e Martinez (2000).

Esses instrumentos foram aplicados aos jovens em sala de aula, cumprindo-se o intervalo de no mínimo um dia e no máximo um mês entre a aplicação de cada teste. A coleta de dados foi realizada no decorrer do ano de 2000.

As aplicações foram autorizadas formalmente pela direção de cada escola participante da pesquisa e consentida livremente pelos pesquisados. Tanto os objetivos deste estudo como sua relevância social foram previamente explicitados. Foi assegurada também, a cada participante, a não divulgação, sob quaisquer circunstâncias, de sua identidade para outras pessoas ou entidades.

\section{Descrição dos Participantes}

A seguir, descreveremos as principais características da população estudada de forma sucinta e geral, pautados, no entanto, em resultados numéricos e testes estatísticos que não serão apresentados de forma integral para que não estendamos em demasia esta apresentação.

Em relação ao sexo: $60,5 \%$ da totalidade é do sexo feminino e $39,5 \%$ do sexo masculino.

No que diz respeito à idade, tanto na amostra proveniente de escolas públicas como na de escolas particulares das três regiões investigadas, a faixa etária está dividida de forma aproximadamente homogênea, mantendo-se a seguinte distribuição: a maioria dos alunos de $8^{\circ}$ ano, do total, encontra-se posicionada na faixa de 13 a 14 anos $\left(77,2^{\%} \%\right)$ e a maioria dos alunos de $3^{\circ}$ ano na de 16 a 17 anos $(79,1 \%)$.

Comparando o nível socioeconômico dos jovens conforme, primeiramente, o tipo de escola freqüentado e, em seguida, a cidade de procedência, constatamos, mediante significância comprovada pelo teste qui-quadrado $(p=0,01)$, que os pais dos jovens de escola pública e os dos jovens de Floriano/PI apresentaram menor nível de escolaridade, com preponderância nos níveis de ensino fundamental e médio; menor posição ocupacional, ocupando predominantemente cargos de produção e de nível médio e possuindo a menor renda mensal (concentração entre 1 a 6 salários mínimos). Por outro lado, os pais dos jovens de escola particular e dos pesquisados de Erechim/RS e Marília/SP apresentaram, de forma geral, maior escolaridade (níveis médio e superior), melhor posição ocupacional, ocupando predominantemente cargos de níveis superior e médio e maior renda mensal (concentração da faixa salarial entre 7 a 12 ou mais de 18 salários mínimos).

Pudemos constatar, assim, a existência de uma desigualdade importante no que diz respeito ao nível socioeconômico entre a amostra proveniente de escolas públicas e a de escolas particulares, e entre os jovens das três regiões investigadas. Essa diversidade indica que os alunos de escolas particulares possuem uma situação socioeconômica mais privilegiada que os de escolas públicas e que, quando comparamos às cidades investigadas, os jovens da região Nordeste enfrentam dificuldades econômicas mais acentuadas do que os das regiões Sudeste e Sul. 


\section{Resultados}

Apresentaremos, primeiramente, os cálculos referentes à fidedignidade da tradução e adaptação do DIT-1 e DIT2 e, em seguida, aqueles que dizem respeito às pontuações obtidas pelos jovens em ambos os testes.

\section{Testes de Fidedignidade da Tradução do Dit-2}

A fim de estimarmos a fidedignidade da tradução para o português do Defining Issues Test -2 (DIT-2), baseados em diversos autores (Anastasi \& Urbina, 2000; Carmines \& Zeller, 1979; Cronbach, 1996; Pasquali, 1997), optamos pela utilização de duas técnicas estatísticas: a correlação $(r)$ e o alfa de Cronbach ( $\boldsymbol{\alpha})$.

Aplicamos o coeficiente de correlação em nossa pesquisa, correlacionando os escores do DIT-1 (versão brasileira) com os do DIT-2 (versão brasileira). Os escores correlacionados foram as pontuações brutas dos testandos em cada Estágio de Desenvolvimento Moral (2, 3, 4, 5A, 5B e 6).

$\mathrm{Na}$ Tabela 1, apresentamos os resultados das correlações entre os escores do DIT-1 e do DIT-2 obtidos na população investigada.
O coeficiente alfa foi calculado, neste estudo, tendo-se por base a pontuação bruta do "índice P" (estágios 5A, 5B e 6) que os testandos obtiveram em cada história. Verificamos o grau de variação dessa pontuação em cada sujeito e entre todos os sujeitos. No DIT-1 foram consideradas as pontuações do "índice P" nas Histórias 01, 02 e 03; no DIT2, nas Histórias 01, 02, 03, 04 e 05. Obtivemos, assim, os seguinte valores:

- DIT-2: $\alpha=0,339$

- DIT-1: $\alpha=0,385$

Observamos que o valor do coeficiente alfa do DIT2 está bem próximo do valor do alfa do DIT-1.

Quando comparamos os resultados do alfa das versões brasileiras do DIT-1 e DIT-2 com os das versões originais americanas, os primeiros (tanto a versão do DIT-1, já utilizada há mais de uma década no Brasil, como a do DIT-2, que acaba de ser concluída) revelam-se bem menores que aqueles obtidos por Rest e colaboradores (1999) em relação ao DIT$1(\alpha=0,78)$ e ao DIT- $2(\alpha=0,70)$.

Esses resultados abrem a possibilidade de se levantarem diferentes suposições e tipos de questionamento.

Tabela 1

Coeficiente de Correlação entre os Escores dos Testes DIT-1 e DIT-2

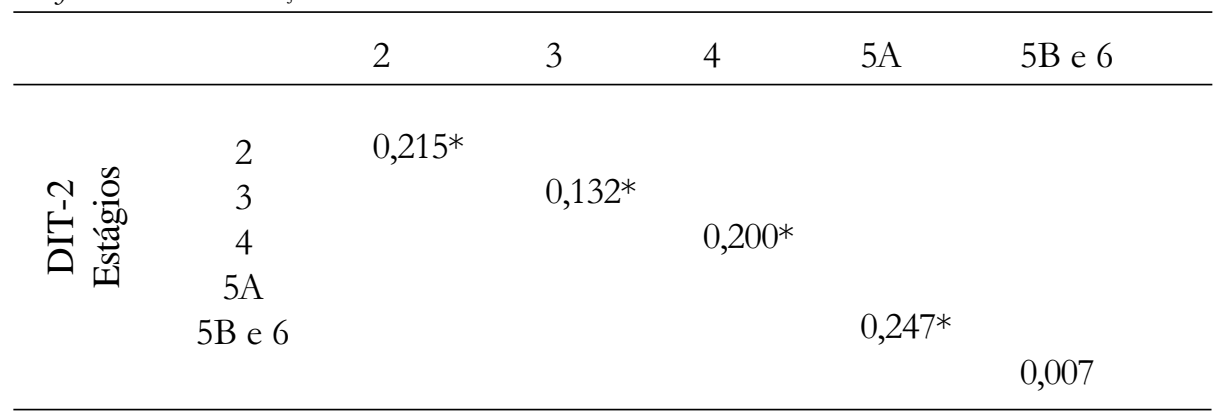

Nota. $\left(^{*}\right)$ os coeficientes que são significativos no nível de significância de 0,01.

Observamos que na maioria dos Estágios (Estágios 2, 3, 4 e $5 \mathrm{~A}$ ) os escores se correlacionam positivamente e de maneira estatisticamente significativa. A pontuação que não se correlacionou (Estágios 5B e 6) foi justamente aquela em que os participantes apresentaram uma média de escore mais baixa e com menor número de itens nos testes. Com base nesses dados, podemos aceitar a hipótese de que o DIT-1 e o DIT-2 se correlacionam de forma estatisticamente significativa. No entanto, os resultados encontrados não são suficientes para se afirmar que os dois testes em questão sejam paralelos, uma vez que, segundo Pasquali (1997, p.135), coeficientes de precisão abaixo de 0,70 não são normalmente suficientes como demonstração de uma fidedignidade aceitável para um teste.
Inicialmente, deve-se interrogar se o índice do coeficiente alfa varia conforme o controle das variáveis: procedência (Sudeste, Sul e Nordeste), tipo de escola (pública e particular) e de nível escolar ( $8^{\circ}$ e $3^{\circ}$ anos).

A fim de buscar responder essa questão, calculamos o índice alfa nessas três situações (DIT-1 e DIT-2). Verificamos que o valor do alfa variou conforme o tipo de variável controlada; no entanto, as únicas variações que demonstraram ser mais significativas e constantes, em ambos os testes, foram as relativas à comparação entre o coeficiente alfa obtido pela amostra do $8^{\circ}$ ano com o alcançado pela amostra do $3^{\circ}$ ano.

Comparemos os resultados obtidos pelos jovens na Tabela 2. 
Tabela 2

Coeficiente Alfa de Cronbach do DIT-1 e DIT-2 conforme o Tipo de Escola, o Ano Escolar Freqüentado e a Procedência da Amostra

\begin{tabular}{lll}
\hline Variáveis & DIT-1 & DIT -2 \\
\hline $8^{\circ}$ ano & $\alpha=0,2986$ & $\alpha=0,2204$ \\
$3^{\circ}$ ano & $\alpha=0,4184$ & $\alpha=0,4106$ \\
Pública & $\alpha=0,3161$ & $\alpha=0,3341$ \\
Particular & $\alpha=0,4151$ & $\alpha=0,3301$ \\
Floriano (PI) & $\alpha=0,3249$ & $\alpha=0,3756$ \\
Erechim (RS) & $\alpha=0,4154$ & $\alpha=0,2751$ \\
Marília (SP) & $\alpha=0,3933$ & $\alpha=0,2919$ \\
\hline
\end{tabular}

Ao analisar-se a Tabela 2, verifica-se que o coeficiente alfa da amostra do $3^{\circ}$ ano é explicitamente superior ao da amostra do $8^{\circ}$ ano. Esses dados indicam que, conforme aumenta o grau de escolaridade e a idade, aumenta o coeficiente de consistência interna do teste.

Com base nesses dados, é necessário questionar-se se o nível de compreensão de leitura por parte dos testandos não seria um fator que poderia estar intrinsecamente relacionado ao resultado do coeficiente alfa e, até mesmo, com os escores obtidos pelos sujeitos em ambos os testes, considerando-se que, como veremos mais adiante na análise dos resultados, a pontuação do DIT-1 e DIT-2 relativa aos estágios de "esquema pós-convencional" (ou "índice P") aumenta conforme a série escolar. Dessa forma, abre-se a possibilidade de que esse teste meça, além do nível de julgamento moral, o nível da capacidade de leitura e interpretação de texto.

Admitindo, hipoteticamente, que o teste seja competente para medir o grau com que os pesquisandos utilizam os diferentes tipos de pensamento moral, indagamos, no entanto, se os participantes que não possuem um bom nível de leitura poderiam ser prejudicados pelo nível de compreensão exigido pelo teste (elevado demais para eles). Esse fator poderia implicar, em certos casos, que a pesquisa realizada por meio do DIT levasse a resultados que não revelariam o real nível de julgamento moral dos pesquisandos, visto acreditarmos que o fator "capacidade de leitura e de interpretação de textos" não é uma condição necessária para o desenvolvimento moral.

Além disso, é possível questionar-se se o DIT-1 e o DIT-2 são adequados à realidade brasileira, uma vez que os resultados do coeficiente alfa obtidos nas amostras americanas são significativamente superiores aos alcançados pela brasileira. Por meio dos dados avaliados, somos levados a acreditar que a versão brasileira do DIT-2 ainda não está satisfatoriamente adequada para ser utilizada como uma versão oficial. Indicamos a necessidade de ser realizada uma melhor adequação do instrumento à realidade do país, buscando eliminar (ou mesmo minorar) essa dificuldade representada pela interpretação das questões a serem respondidas.

A experiência obtida na utilização desse instrumento em nossa pesquisa possibilitou-nos observar os primeiros aspectos do teste que talvez devessem ser modificados, a fim de possibilitar a sua adequação à realidade brasileira.

Em relação ao conteúdo do teste, notamos uma dificuldade por parte dos participantes da pesquisa em entender a História 5, referente ao protesto de estudantes universitários diante da atitude do governo norte-americano de utilizar o poder da força militar para obter vantagem econômica. Observamos que não só o tema (excessivamente distante do contexto brasileiro) como também a forma como essa história está redigida no teste são de difícil compreensão pelos jovens brasileiros. Na versão brasileira do DIT-2, portanto, uma cuidadosa revisão, ou mesmo a substituição dessa história por uma outra, mais adequada ao contexto de nossos jovens, provavelmente aumentaria a eficácia do teste como meio de investigação de seu nível de julgamento moral.

No que diz respeito à estrutura do teste, pudemos observar que as doze questões (que devem ser julgadas pelos sujeitos conforme seu grau importância) apresentadas logo após cada história acabam por confundir os testandos por estarem na forma interrogativa. Vários participantes perguntavam se deveriam responder às questões; outros, em vez de avaliar o grau de importância, responderam-nas, tarefa que não é pedida no teste. Sugerimos, então, que essas questões passem da forma interrogativa para a afirmativa.

Essa transformação eliminaria, ao mesmo tempo, outro aspecto que também despertou dúvidas nos participantes da pesquisa: o uso do advérbio "não" em algumas das questões. A questão 1 da História 2, por exemplo, interroga se "O público não tem o direito de conhecer todos os fatos a respeito dos candidatos a um cargo?”; a questão 9 da História 4: "O médico não se sentiria culpado por dar tanto remédio à Sra. Neuza a ponto de ela morrer?" ou ainda a questão 10 da História 5: "As autoridades não deveriam ser respeitadas pelos estudantes?" Apesar de o advérbio "não" ter sido utilizado, nesses casos, apenas como partícula de realce, vários jovens perguntaram se essa palavra exprimiria negação, o que alteraria o sentido da frase.

É necessário notar, no entanto, que foi possível observar algumas vantagens do DIT-2 em relação ao DIT-1. O DIT2 demonstrou-se mais rigoroso e pertinente no que diz respeito aos critérios utilizados para certificar se as respostas de cada testando são confiáveis ou questionáveis. Para esse fim, os critérios utilizados pelo DIT-2 são: o nível de consistência entre o grau de importância dado às 12 questões que acompanham cada história e as quatro questões apontadas 
pelo testando como as mais importantes; número de vezes que o testando escolhe como uma das quatro mais importantes as questões denominadas "índice M" (que estão no teste apenas para verificar se o sujeito o está preenchendo com atenção e seriedade, visto serem itens que não possuem sentido no contexto da história de referência); número de vezes em que o testando deixa em branco as 12 questões após cada história; número de vezes em que não são indicadas as quatro questões mais importantes de cada história e freqüência com que o testando não faz diferenciação de respostas, seja no grau de importância dado às 12 questões (como, por exemplo quando o testando atribui importância "média" a todas as questões da História " $x ")$, seja na escolha das quatro questões mais importantes (quando, por exemplo, uma única questão é apontada como a primeira, a segunda, a terceira e a quarta mais importante em relação à História "x") - para maiores detalhes consultar o Guide for DIT -2 de Rest e Narvaez (1998).

Apesar de no manual do DIT-1 (Rest, 1986) encontrarmos referência apenas aos dois primeiros critérios de confiabilidade acima citados, o número de DIT-1 invalidados foi $12 \%$ superior ao do DIT-2. Atribuímos como fator causal dessa ocorrência a forma como os itens $\mathrm{M}$ estão redigidos no DIT-1, visto que a maior parte das invalidações deu-se por exceder-se a pontuação mínima aceita para esse índice. No DIT-1 foi muito maior o número de invalidação de questionários devido à escolha de itens $\mathrm{M}$ pelos testandos do que no DIT-2.

As questões do tipo M no DIT-1 são: as de $\mathrm{n}^{\circ} 4$ e 7 na História 1, no 6 na História 2 e n 5 na História 3; e no DIT2: as de $n^{\circ} 8$ na História $1, n^{\circ} 9$ na História $2, n^{\circ} 4$ na História 3 en ${ }^{\circ} 5$ na História 4 . Ao avaliarmos as questões apresentadas no DIT-1, constatamos que, diferentemente do que ocorre no DIT-2, algumas delas na realidade não podem ser consideradas sem sentido em relação ao contexto da história da qual fazem parte - sobretudo as questões: $n^{\circ} 4$ na História 1 ("João deve considerar que é importante a qualidade de vida.") e no 8 na História 3 ("O Diretor tem a liberdade para conversar com os pais dos alunos").

Sugerimos, assim, que se realize uma revisão desse aspecto do DIT-1, uma vez que a invalidação desnecessária de instrumentos prejudica operacionalmente a pesquisa, aumentando seu custo e seu tempo de execução.

\section{Pontuações no DIT-1 e DIT-2}

Os escores do DIT-1 e DIT-2 foram analisados de forma a apurarmos as pontuações médias dos jovens, conforme o ano escolar e o tipo de escola freqüentado e a cidade de procedência, em cada estágio de raciocínio de julgamento moral (Estágios 2, 3, 4 5A, 5B e 6) e a pontuação média em porcentagem do "índice P" (Estágios 5A, 5B e 6).
Nos gráficos abaixo reproduzidos apresentamos a distribuição média da pontuação bruta em cada estágio de raciocínio de julgamento moral (Estágios 2, 3, 4, 5A, 5B e 6) nos DIT-1 e DIT-2 dos jovens brasileiros, conforme o tipo de escola freqüentado.

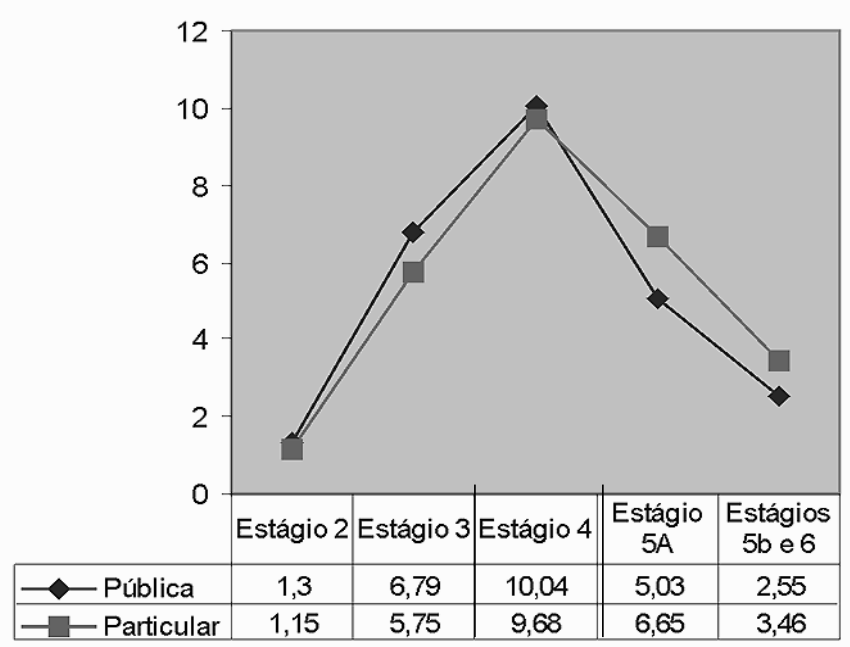

Figura 1. Pontuação média bruta dos jovens brasileiros de escola pública e particular no DIT-1.

A Figura 1 demonstra que a maior pontuação dos jovens de ambos os tipos de escola concentrou-se no Estágio 4. Verificamos também que os alunos de escola pública alcançaram maior pontuação em relação aos de escola particular nos Estágios mais baixos (Estágios 2 e 3), ao passo que os de escola particular obtiveram maior pontuação em relação aos alunos de escola pública nos Estágios mais altos (5A, 5B e 6).

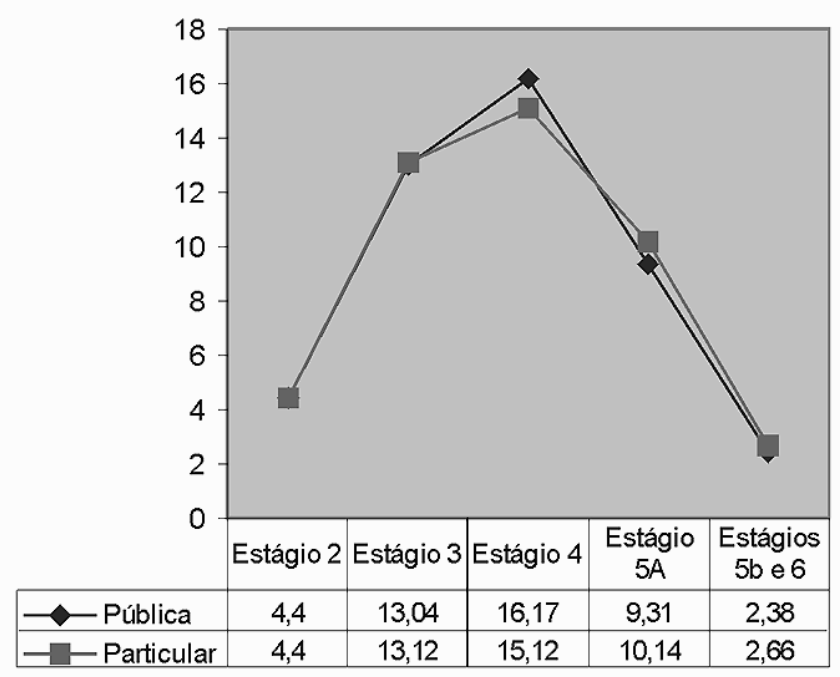

Figura 2. Pontuação média bruta dos jovens brasileiros de escola pública e particular no DIT-2. 
Em relação à pontuação alcançada pelos pesquisados no DIT-2 observamos, na Figura 2, ter-se concentrado no Estágio 4, em ambas as amostras. No que diz respeito aos estágios mais baixos (Estágios 2 e 3), a pontuação entre os jovens dos dois tipos de escola foi praticamente equivalente; no entanto, os jovens de escola particular obtiveram uma pontuação maior quando nos estágios mais altos $(5 \mathrm{~A}, 5 \mathrm{~B}$ e 6), comparada à média dos de escola pública.

Quanto à pontuação média em porcentagem do "índice P" (Estágios 5A, 5B e 6) nos DIT-1 e DIT-2, constatamos que os alunos de escola particular obtiveram uma média maior do que os de escola pública, tanto no DIT-1 quanto no DIT-2. Enquanto os jovens de escola particular alcançaram uma média em porcentagem do "índice P" de $32,12 \%$ no DIT-1 e de $25,62 \%$ no DIT-2, as médias obtidas pelos jovens de escola pública foram $25,69 \%$ no DIT-1 e $23,04 \%$ no DIT-2. Aplicando o teste $t$ de student, obtivemos, para o DIT-1, $t=4,89$ e para o DIT-2, $t=2,58$, indicando, assim, que as diferenças entre as médias dos alunos de escola pública e de escola particular são significativas para $p=0,01$.

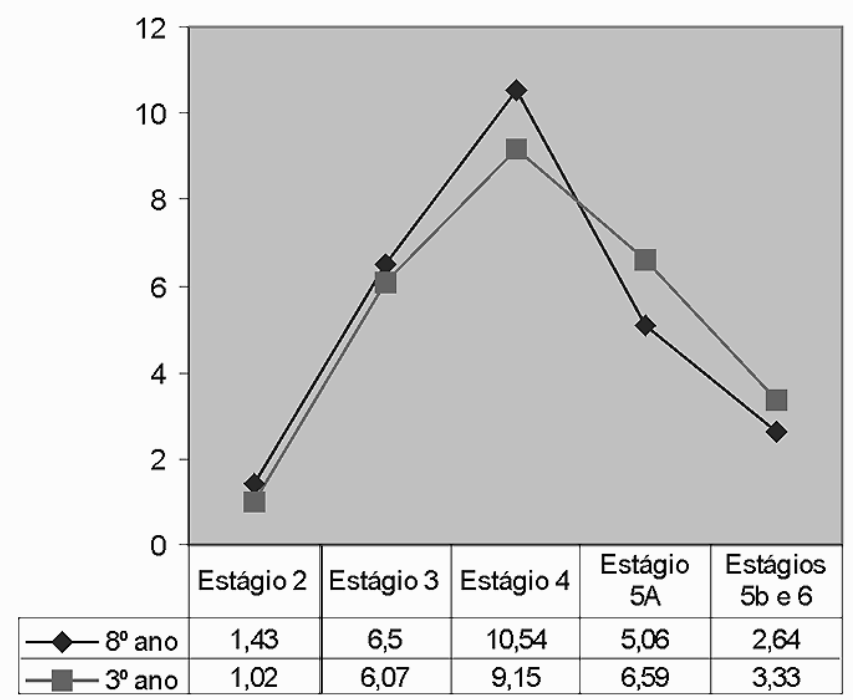

Figura 3. Pontuação média bruta dos jovens brasileiros de $8^{\circ}$ ano e $3^{\circ}$ ano no DIT-1.

Em relação às diferenças de pontuações médias dos jovens de $8^{\circ}$ e $3^{\circ}$ ano no DIT-1, observamos, na Figura 3 , que para ambas as amostras a maior pontuação média obtida foi no Estágio 4. Em relação aos demais Estágios, enquanto os jovens do $8^{\circ}$ ano, quando comparados aos de $3^{\circ}$ ano, obtiveram pontuações ligeiramente maiores nos Estágios 2 e 3 , os de $3^{\circ}$ ano, quando equiparados aos de $8^{\circ}$ ano, obtiveram pontuações visivelmente superiores nos Estágios $5 \mathrm{~A}, 5 \mathrm{~B}$ e 6.

Em relação ao DIT-2, observamos novamente uma pontuação média maior no Estágio 4. Quando confrontamos

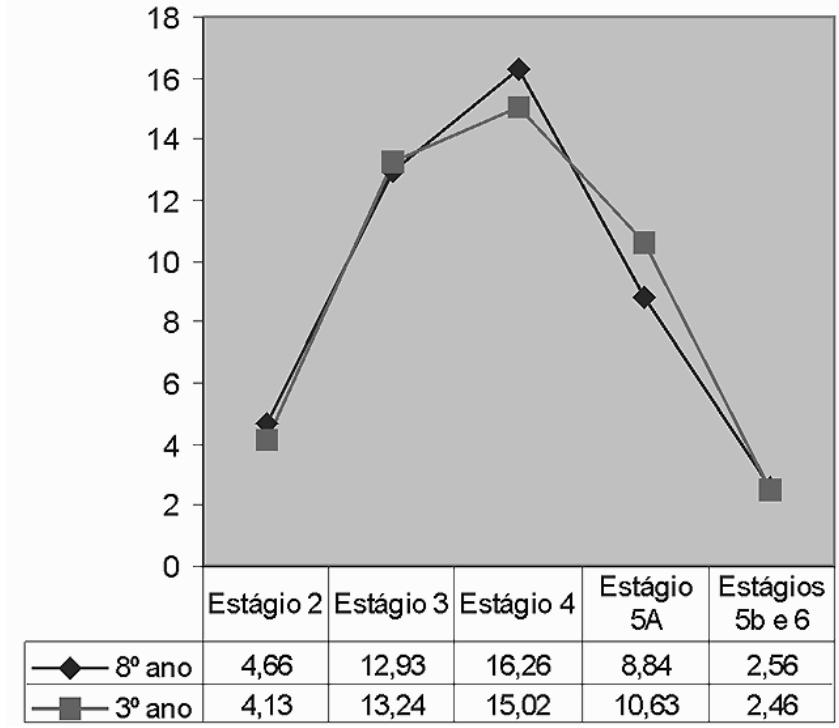

Figura 4. Pontuação média bruta dos jovens brasileiros de $8^{\circ}$ ano e $3^{\circ}$ ano no DIT-2.

as medias dos jovens de $\mathrm{c}^{-}$ano com os de $\mathrm{J}^{-}$ano, observamos que, enquanto no Estágio $5 \mathrm{~A}$ os jovens do $3^{\circ}$ ano apresentaram uma pontuação superior, nos demais Estágios $(2,3,5 \mathrm{~b}$ e 6$)$ as diferenças foram menos marcantes.

Em relação à pontuação média em porcentagem do "índice P" (Estágios 5A, 5B e 6) nos DIT-1 e DIT-2, constatamos que os alunos de $3^{\circ}$ ano apresentaram uma média superior aos de $8^{\circ}$ ano, tanto no DIT-1 quanto no DIT-2. Enquanto aqueles obtiveram uma média em porcentagem do "índice P" de $32,26 \%$ no DIT-1 e de $26,20 \%$ no DIT-2, as médias destes foram $25,42 \%$ no DIT-1 e $22,81 \%$ no DIT-2. Aplicando o teste $t$ de student, obtivemos, para o DIT-1, $t=5,21$ e para o DIT-2, $t=3,94$, indicando, assim, que as diferenças entre as médias dos alunos de $3^{\circ}$ ano e de $8^{\circ}$ ano são significativas para $p=0,01$.

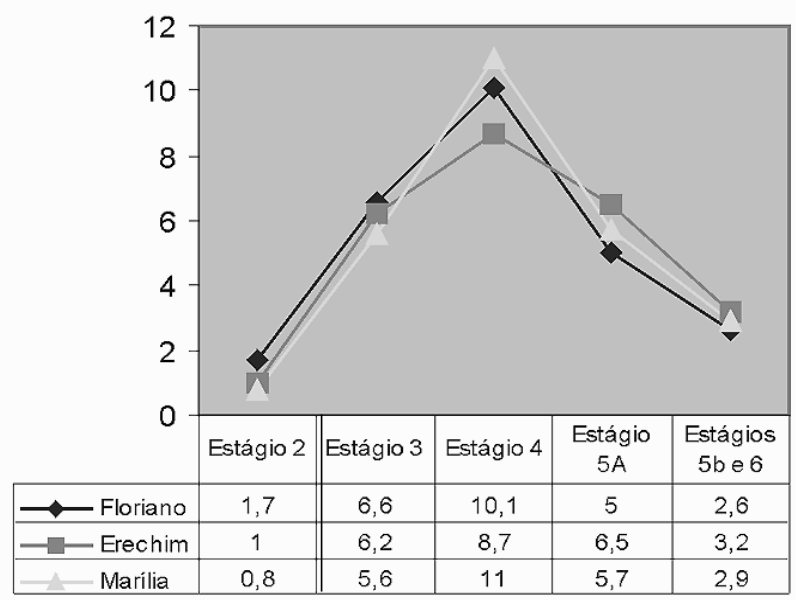

Figura 5. Pontuação média bruta dos jovens brasileiros de Floriano/PI, Erechim/RS e Marília/SP no DIT-1. 
Nesta Figura 5, notamos que a maior pontuação média obtida pelos jovens das três regiões investigadas foi no Estágio 4. Em seguida, constamos que, quando comparamos as pontuações das três cidades, foram os pesquisados de Floriano/ PI que obtiveram maior pontuação nos Estágios 2 e 3 e menor pontuação nos Estágios $5 \mathrm{~A}, 5 \mathrm{~B}$ e 6 . Por outro lado, a maior pontuação nos Estágios 5A, 5B e 6 foi alcançada pelos jovens de Erechim/RS e em seguida pelos de Marília/SP; o menor escore nos Estágios 2 e 3 foi realizado pelos pesquisandos de Marília/SP e, em segundo lugar, pelos de Erechim.

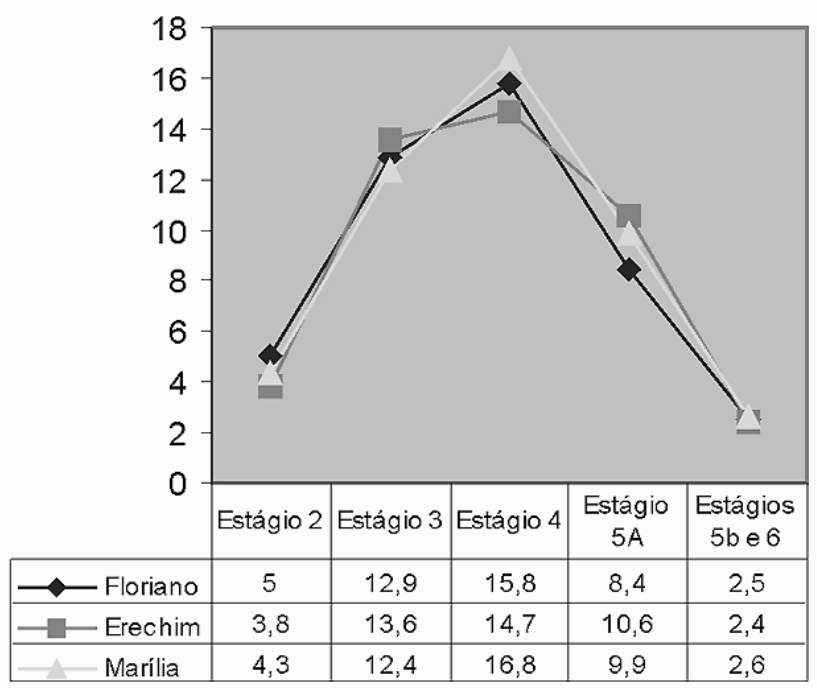

Figura 6. Pontuação média bruta dos jovens brasileiros de Floriano/PI, Erechim/RS e Marília/SP no DIT-2.

Em relação ao DIT-2 notamos, novamente, o Estágio 4 representando a maior pontuação média alcançada por todos os grupos quando a comparamos com aquelas obtidas nos demais Estágios. Analisando comparativamente os jovens das três regiões, observamos que as diferenças mais significativas foram aquelas encontradas nos Estágios 2 e 5 A: os pesquisandos de Floriano/PI apresentaram maior pontuação no Estágio 2 e menor no Estágio $5 \mathrm{~A}$ e os de Erechim/RS menor pontuação no Estágio 2 e maior no Estágio 5A. Os jovens de Marilia/SP, por sua vez, ocuparam uma posição intermediária em ambos os Estágios.

No que diz respeito à pontuação média em porcentagem do "índice P", observamos que as menores pontuações tanto no DIT-1 como no DIT-2 foram obtidas pelos jovens de Floriano/PI - respectivamente $25,87 \%$ e $21,9 \%$. Por outro lado, as maiores pontuações desse mesmo índice em ambos os testes foi a dos pesquisados de Erechim/RS (31,9\% e 26,13\%). Os jovens de Marilia/SP, por sua vez, apresentaram, novamente, uma pontuação intermediária $(27,76 \%$ e
25,10\%). Aplicando-se uma ANOVA, observamos que as diferenças apresentadas foram significantes $(p=0,01)$, tanto no DIT-1 $(F=7,94)$ como no DIT-2 $(F=8,84)$.

\section{Discussão}

Apesar de os resultados dos testes de fidedignidade das traduções do DIT-1 e DIT-2 demonstrarem ser inferiores àqueles obtidos nas versões originais americanas, observamos que os testes são sensíveis ao controle das variáveis selecionadas em nossa pesquisa (status socioeconômico, nível educacional e região de procedência), apontando para tendências distintas no interior da amostra investigada.

Verificamos também que essas tendências coincidem com os estudos de Rest e colaboradores (1999), que indicam a existência de uma diferenciação de grupos em relação a medidas mais altas ou mais baixas de julgamento moral especialmente, segundo pesquisas desses autores, em relação à variável nível educacional (o que questionaremos mais adiante) - e com o trabalho de Koller e colaboradores (1994) em que, em uma pesquisa aplicando o DIT-1 a 298 jovens de várias Regiões do Brasil, os do Sul e do Sudeste apresentaram um nível de julgamento moral mais alto que os da região Nordeste.

Em Shimizu (2002), realizamos uma análise comparativa entre as pontuações no DIT-1 e no DIT-2, apresentadas no presente estudo, e as representações sociais que essa mesma amostra pesquisada apresenta em relação a diferentes aspectos sociomorais, conforme o tipo de escola e o ano escolar freqüentado. Os resultados demonstraram que, quando confrontamos as representações sociais e o nível de julgamento moral dos jovens de escola pública e escola particular, as tendências encontradas são bastante marcantes e coincidentes com aquelas apuradas no DIT-1 e DIT-2.

Os jovens de escola pública, além de alcançarem pontuações maiores do que os de escola particular nos Estágios 2 e 3, em suas representações enfatizam uma moral mais voltada ao âmbito pessoal, representando personagens e características de moralidade que dizem respeito a relações próximas e familiares e à supressão das necessidades básicas intrínsecas a essas esferas; concebem a lei como uma obrigação a ser cumprida e respeitada para a manutenção da ordem social, devendo prescrever deveres; e a justiça, principalmente, como a responsável pela garantia do respeito à lei, pelo cumprimento dos deveres nela prescritos.

Por outro lado, os jovens de escola particular além de obterem maiores pontuações nos Estágios $5 \mathrm{~A}, 5 \mathrm{~B}$ e 6 , enfatizam a formação de valores éticos e princípios morais como a justiça; personificam a moralidade em pessoas do âmbito familiar, mas ancoram-na também em personagens históricos; concebem a lei como um direito constitucional 
que deve assegurar a proteção dos direitos de todos e a justiça como um direito legal, que tem a obrigação de garantir a igualdade de direitos.

Em relação à análise das representações sociais de moral e do nível de julgamento moral dos jovens brasileiros conforme o ano escolar freqüentado, também em Shimizu (2002) observamos que as variações no DIT-1 e DIT-2 seguiram as mesmas tendências encontradas entre os alunos de escola pública e particular, sendo que as dos jovens de $8^{\circ}$ ano ficaram mais próximas às dos de escola pública e as dos alunos de $3^{\circ}$ ano, às dos de escola particular. No entanto, no que se refere às representações sociais e suas redes de significações, notamos, de forma geral, que as variações foram menos marcantes do que aquelas reveladas nas comparações entre os alunos de escola pública e particular.

A partir dessas constatações, perguntamo-nos se essas diferenças entre as representações e o DIT-1 e DIT-2 não se devem, sobretudo, à problemática que enfocamos ao verificar o coeficiente de consistência interna dos testes naquele momento em que sugerimos que o DIT-1 e o DIT2 poderiam, muitas vezes, medir, além do nível de julgamento moral, o nível de compreensão de leitura e interpretação de texto (ou mesmo o desenvolvimento cognitivo) do pesquisando.

Rest e colaboradores (1999) afirmam que, quanto maior for o nível de julgamento moral, mais consistentes serão as respostas dos pesquisandos. Questionamos, então, por que as diferenças entre os coeficientes de consistência interna foram relevantes somente quando realizamos comparações entre o grau de escolaridade, e não entre o tipo de escola freqüentado, se em ambas os tipos de variáveis os escores do DIT-1 e DIT-2 apresentaram variações e tendências semelhantes. A única resposta que encontramos para essa questão é a de que os níveis cognitivo e de leitura podem exercer influência significativa na forma como esses testes são respondidos.

Os dados que discutimos acima sugerem que o DIT-1 e o DIT-2 podem nos revelar e confirmar diferentes formas de moralidade e de julgamentos morais mas, também, podem - especialmente quando utilizados como únicos instrumentos de investigação - conduzir-nos a conclusões equivocadas e estereotipadas. Dessa forma, conclui-se que a utilização de instrumentos de medida objetivos e fechados deve-se dar acompanhada de muita cautela.

Outro aspecto relevante é a forma como os resultados obtidos por esses testes podem ser interpretados. Acreditamos que a nós pesquisadores cabe a tarefa de buscar compreender e revelar os aspectos que envolvem o imaginário e a experiência cotidiana dos indivíduos que pesquisamos, sem, no entanto fixá-los em graduações. Neste estudo, as diferenças encontradas em relação ao tipo de escola freqüentada (pública e particular) e quem sabe, em relação à Região de procedência, que não aprofundamos como no primeiro caso, marcadas, como verificamos na caracterização de nossa amostra, pela desigualdade socioeconômica, podem ser explicadas também com base em diversos autores que procuram entender como se dá o funcionamento da sociedade brasileira.

Pautados em alguns desses estudiosos (especificamente em Damatta, 1987, 1991; Jovchelovitch, 2000; Souza, 1999) podemos deduzir que entre os jovens melhor posicionados na sociedade existe uma maior possibilidade de se buscar a autonomia no espaço público, reivindicar-se um lugar e direitos nas instituições legais e nas relações sociais mais amplas. Aos jovens brasileiros que carregam as marcas de pertencerem a classes de status socioeconômico inferiores, cabem as dificuldades para conquistar um espaço digno em nossa sociedade, sujeita às regras de uma "igualdade desigual". As possibilidades de se alcançar alguma autonomia, para os jovens de classes socioeconômicas desprivilegiadas, existem; porém, são mais realizáveis nos ambientes em que se pode conhecer o real significado de "ser alguém" - ou seja, nas relações sociais mais próximas, na casa, no bairro periférico, no "morro", enfim.

\section{Referências}

Anastasi, A. \& Urbina, S. (2000). Testagem psicológica. Porto Alegre: Artes Médicas. Biaggio, A. M. B., Shimizu, A. M \& Martinez, T. M. (2001). DIT-2 Opiniões sobre Problemas Sociais: Tradução e Adaptação do Defining Issues Test-2. Minneapolis, MN, USA: Center for the Study of Ethical Development - University of Minnesota. (Autores da versão original: J. Rest \& D. Narvaez, 1998)

Bzuneck, J. A. (1979). Julgamento moral de adolescentes delinqüentes e não delinqüentes em relação com a ausência paterna. Tese de Doutorado não- publicada, Curso de Pós-Gradução em Psicologia Escolar, Universidade de São Paulo. São Paulo, SP.

Camino, C. \& Luna, V. (1989, junho). Reformulação e adaptação do Defining Issues Test (DIT). Trabalho apresentado no Congresso Interamericano de Psicologia, Buenos Aires, Argentina.

Carmines, E. G. \& Zeller, R. A.(1979). Reliability and validity assessment. California: Sage.

Cronbach, L. J.(1996). Fundamentos da testagem psicológica. Porto Alegre: Artes Médicas.

Damatta, R. (1987). A casa \& a rua: Espaço, cidadania e morte no Brasil. Rio de Janeiro: Guanabara.

Damatta, R. (1991). O que faz o brasil, Brasil? Rio de Janeiro: Rocco.

Jovchelovitch, S. (2000). Representações sociais e esfera pública: A construção simbólica dos espaços públicos no Brasil. Petrópolis: Vozes.

Kohlberg, L. (1992). Psicologia del desarrollo moral. Bilbao, Espanha: Editorial Desclée de Brower.

Koller, S. H., Biaggio, A. M. B., Lopes, S., Rique, J. N., Camino, C., Dias, M. G. \& Costa, A. E. (1994). Uma investigação sobre os instrumentos de medida de maturidade de julgamento moral em uso no Brasil. Psicologia: Reflexão e Crítica, 7, 5-14.

Lind, G. (2000). O significado e medida da competência moral: Um modelo de duplo aspecto da competência moral. Psicologia: Reflexão e Crítica, 13, 399416.

Pasquali, L. (1997). Psicometria: Teoria e aplicações. Brasília: Universidade de Brasília. 
Rest, J. (1986). DIT Manual: Manual for the Defining Issues Test. Minneapolis: University of Minnesota.

Rest, J. \& Narvaez, D. (1998). Guide for DIT - 2. Minneapolis: Center for the Study of Ethical Development, University of Minnesota.

Rest, J. , Narvaez, D., Bebeau, M. J. \& Thoma, S. J. (1999). Postconventional moral thinking: A neo-koblbergian approach. Mahwah: Lawrence Erlbaum.

Shimizu, A. M. (2002). Representações sociais e julgamentos morais de jovens: Um estudo intercultural comparando duas abordagens teórico-metodológicas. Tese de Doutorado não-publicada, Curso de Pós-graduação em Educação, Universidade Estadual Paulista. Marilia, SP.
Souza, M. (1999). A experiência da lei e a lei da experiência: Ensaios sobre práticas sociais e subjetividade no Brasil. Rio de Janeiro: Revan.

Sobre a autora

Alessandra de Morais Shimizu é Psicóloga, Mestre e Doutora em Educação pela Universidade Estadual Paulista, Campus de Marília, SP. Bolsista da Capes pelo Programa de Absorção Temporária de Doutores (ProDoc) junto ao Programa de Pós-Graduação em Educação da Universidade Estadual Paulista, Campus de Presidente Prudente, SP. 